Volume 9, No.4, July - August 2020

International Journal of Advanced Trends in Computer Science and Engineering

Available Online at http://www.warse.org/IJATCSE/static/pdf/file/ijatcse32942020.pdf

https://doi.org/10.30534/ijatcse/2020/326942020

\title{
Leveraging IoT towards Sustainable Manufacturing Applications Based on Text Analytics
}

\author{
Sharifah Sakinah Syed Ahmad ${ }^{1}$, Zuraini Othman ${ }^{2}$ and Fauziah Kasmin ${ }^{3}$ \\ ${ }^{1}$ Assistant Professor, Department of Intelligent Computing \& Analytics (ICA), Fakulti Teknologi Maklumat Dan \\ Komunikasi, Universiti Teknikal Malaysia Melaka (UTeM), 76100 Durian Tunggal, Melaka, Malaysia \\ (Email id:sakinah@utem.edu.my)
}

${ }^{3}$ Senior Lecturer, Department of Intelligent Computing \& Analytics (ICA), Fakulti Teknologi Maklumat Dan Komunikasi, Universiti Teknikal Malaysia Melaka (UTeM), 76100 Durian Tunggal, Melaka, Malaysia

(Email id:zuraini@utem.edu.my)

\begin{abstract}
${ }^{4}$ Senior Lecturer , Department of Intelligent Computing \& Analytics (ICA), Fakulti Teknologi Maklumat Dan Komunikasi, Universiti Teknikal Malaysia Melaka (UTeM), 76100 Durian Tunggal, Melaka, Malaysia (Email id:fauziah@utem.edu.my)
\end{abstract}

\begin{abstract}
Latest advancements in the Internet of Things (IoT) setup and the advent of the sensing technology have generated an integrated information data which could be employed for enhancing the manufacturing sector. The blend of cyber-physical systems and intelligent data analytics is playing a key part in product management as well as factory transformation. The advanced analytics technique for data purposes could facilitate self-awareness and self-maintenance of factory machines. In this case, self-awareness for a mechanical structure pertains to the ability to evaluate the machine's present and historical condition and deploy available information for responding to its condition. The machine's well-being can be ascertained by employing the data analytic technique centred on the gathered information or data from the machine and surrounding environment. The data-propelled decision-making process can provide feedback to the machine controller for effectual and adaptive control and to machine owners for the in-time upkeep. This paper discusses the application of data and text analytic methodology in an orderly literature review of papers pertaining to the deployment of IoT methodology in the production sector. The chosen papers are exposed to content evaluation and grouped as per the modern technologies and functions. The research espoused determines trends of IoT deployment in the production sector and notes that text analytic is an effectual technique for carrying out an orderly literature review.
\end{abstract}

Key words: Internet of things, smart manufacturing, data analytics, systematic literature review, cyber-physical system

\section{INTRODUCTION}

In the era of Industry 4.0 and the digital revolution, the production sector has noted the highest number of applications of the Internet of Things (IoT). As per a new article by Louis Columbus on forbes.com, the worldwide IoT market would rise from $\$ 157$ billion in 2016 to $\$ 457$ billion by 2020 , at a compound annual growth rate (CAGR) of $28.5 \%$ [1]. Share of IoT use in industrial production is estimated to rise from $\$ 472$ billion in 2014 to $\$ 890$ billion in 2020 [1]. The deployment of IoT presents swift returns and facilitates attainment of digital revolution from multiple angles: automation, performance, customer-focus and competitive advantage. The makeover enables factory operators to automatically gather and evaluate data for making better- decisions and optimising output. The data from machines and sensors is conveyed to the Cloud through IoT connectivity solutions employed in the industrial unit [2][3][4][5]. The IoT technology, capitalising on wired as well as wireless connectivity, facilitates this data flow, rendering the capability to remotely observe and regulate practices and alter manufacturing plans fast, in real time when required [6][7][8]. These kinds of innovations, coupled with the improvements in predictive analytics, are altering the core element of the cutting-edge sector [9][10][11][12].

An advanced data analytics and physical machinery known as cyber-physical systems (CPS) is used in regulating the production process [13][14][15][16]. Here, the data is scrutinised and blended with contextual 
info and then communicated to official stakeholders [17][18]. It significantly enhances the consequences of production in the form of decreasing waste, amplifying production, and enhancing yield as well as the quality of goods manufactured.

The significance of applying IoT to the production sector has been discussed exhaustively by experts in recent times. This paper would do a methodical literature review about applying IoT to the production sector. Up till now, not much focus has been applied to review this subject, especially in the academic field. This paper elucidates our analysis of the different contributions by IoT applications in the production sector. The organisation of this paper begins with the backdrop of IoT in production. A synopsis of our research approach is then presented. The following sections provide the descriptive as well as text analysis for the research articles published. Lastly, we summarise the contributions of this work and suggest future works.

\section{MATERIALS AND METHODS}

The research regarding the recent publication pertaining to the subject of IoT application in the production sector is quite significant for supporting the information related to the newest technology and applications associated with the chosen topic. By executing the methodical literature review, this topic will put across future research in the domain, by substantiating trends and newest technologies utilised in addressing the IoT complications in production.

The practice of systematic search begins with the ascertainment of the appropriate keyword and search term pertaining to the scope of the work. The data collection is an iterative procedure which encompasses many steps depicted in Figure 1. The time range chosen for the publications was five years (January 2014 to December 2018). This is a crucial range to respond to our first goal of looking at the trends for production system and the use of latest technology like data analytics modelling and the Internet of Things (IoT). English was chosen as the primary language as the majority of the literature is in this language. The main keywords used by us are Internet of Things and manufacturing. Next, the words which would be utilised between keywords and the search field are AND and OR Boolean operators. For instance, in the title, abstract, and keywords, we deployed ("manufacturing" AND "Internet" AND "Of" AND "Things") and the word "OR" for linking the databases. Table 1 depicts the review protocol outlined to return a tangible outcome on the topic being researched.

Table 1: Review protocol

\begin{tabular}{|l|l|}
\hline Item & Description \\
\hline Keywords & Manufacturing; Internet of Thing \\
\hline Boolean Operators & $\begin{array}{l}\text { AND keywords; } \\
\text { OR between Database search fields }\end{array}$ \\
\hline Search Fields & Title; Abstract; Keywords \\
\hline Language & English \\
\hline Publication Type & Article \\
\hline Time Range (Years) & 2015 to 2019 \\
\hline Databases & Scopus \\
\hline
\end{tabular}

Stage 1: Define
- Step 1: Identification of need for a literature review
- Step 2: Development of a literature review protocol
Stage 2: Collect and Select
- Step 1: Identification of documents
- Step 2: Selection of relevent documents
Stage 3: Analysis and Findings
- Step 1: Categorization of documents
- Step 2: Data extraction
- Step 3: Descriptive analysis
Stage 4: Rext analysis
- Document findings

Figure 1: Phases in systematic literature review [19] [20]

The total number of papers acquired is 2650 following submission of the search string in the databases. The text analysis aids in choosing the best paper which meets the goals of the research conventions. Next, we choose 148 papers to exert greater emphasis on the latest technology, and research has been carried out on this subject for further scrutiny.

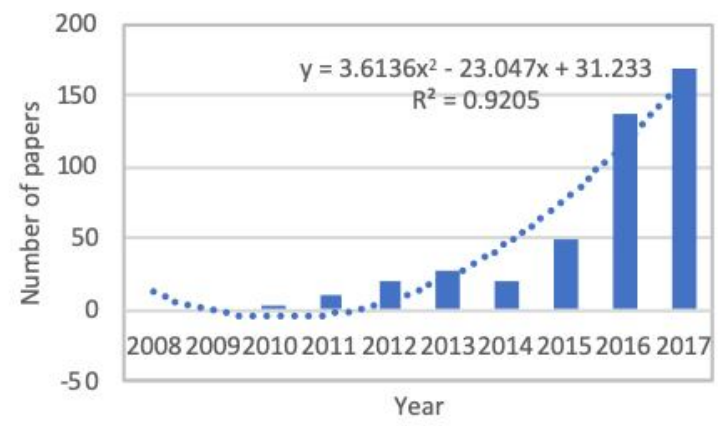

Figure 2: Papers published in Scopus

The selected studies are sorted into 3 categories according to year of publication. Figure 2 displays the studies selected based on year. Such information is key to establishing the research trend in this field. Article distribution according to publication type is displayed in Figure 3. In this research, text analytic strategy enables 
the identification of those manufacturing industries which allow enabling IoT applications. Furthermore, the latest technologies implemented in IoT applications are presented in the visualisation according to text analytic strategy.

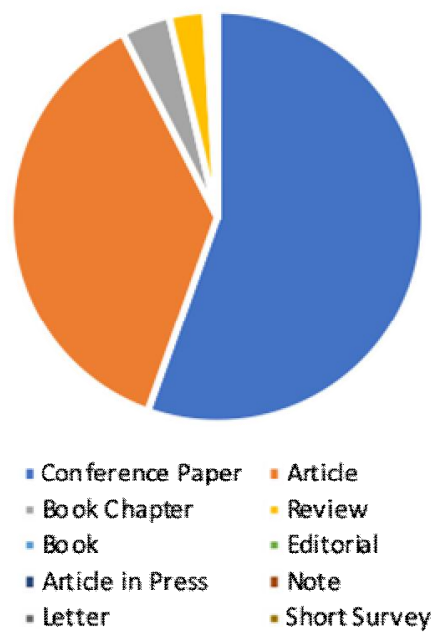

Figure 3: Article distribution by publication type

\section{RESULTS AND DISCUSSION}

\subsection{Text Analysis Review}

Text analysis is conducted after the data collection process and the results are used to examine the most commonly-used phrases found in IoT-related publications that cover manufacturing systems. The text list is then collected from the abstracts and keywords of all related journals. Several word types are excluded so as to minimise bias in the text analysis process, namely "IOT", "Manufacturing", and "Internet of Things". All stop words are similarly excluded from the word list, for these represent the most popular words in the language [21]. In this investigation, 2 different word sources are used for each publication. The first type is derived from the title column, whereas the second derived from the keyword column. Figure 4 shows the 1-gram word cloud of all titles for 2650 journals related to IoT and manufacturing. The words "internet" and "industry" are the highest and second highest in frequency, respectively. Figure 5 shows more detail on the numbers and frequencies of words used in various titles.

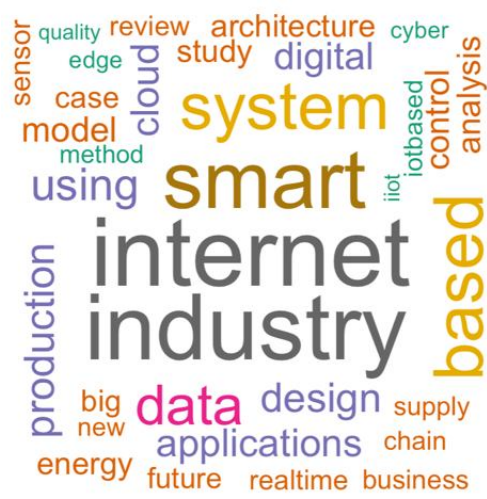

Figure 4: A 1-gram word cloud of the title in 2650 publications

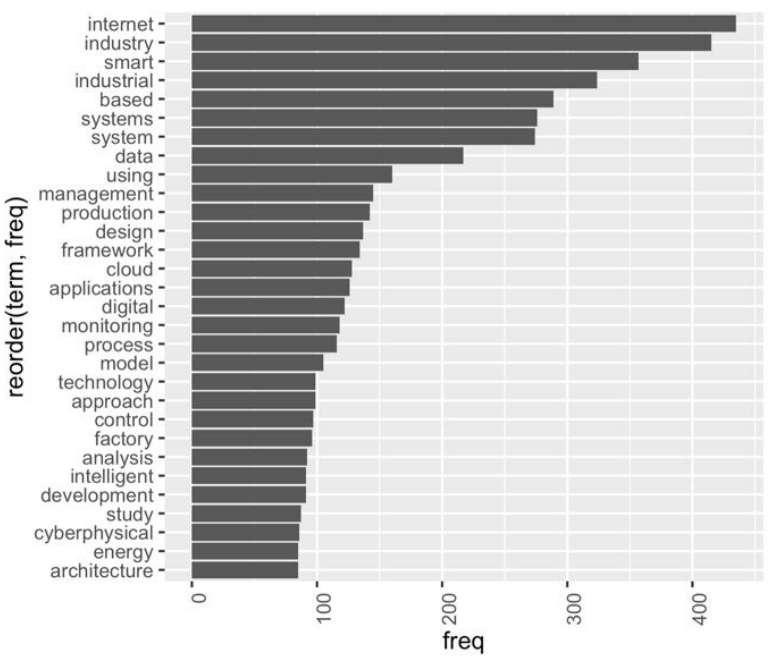

Figure 5: A frequency of words used in the title in 2650 publications

Figure 6 displays the most frequent words derived from the abstract and keyword columns, using the 1-gram model and with visualisation based on the word cloud strategy. Word clouds offer powerful visualisations in text analysis that describe the most commonly-used words found in any publication abstract. Among the most popular are "internet" and "data", which describe backbone processes in manufacturing IoT applications. Both word clouds show word consistency in related publications. The words "industrial, "internet", "smart", and "system" all appear in both word clouds. Visualisation of such words found in an abstract help determine the key topic to be considered for further research. Furthermore, industry players already realise IoT implementations in industrial manufacturing. Such operations comprise numerous elements that typically include Manufacturing Operations Management (MOM), intelligent manufacturing, asset management, and human-machine interactions, as well as performance monitoring, planning, and optimisation that provide end-to-end operational visibility in such industrial systems, as established in Industry 4.0. 


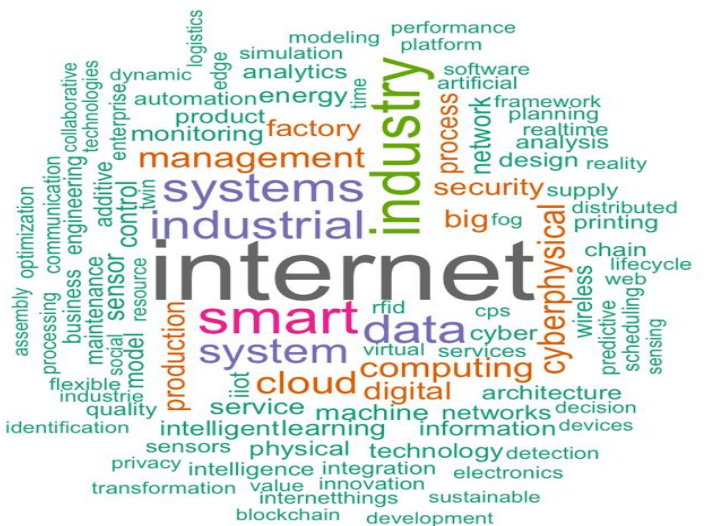

(a)

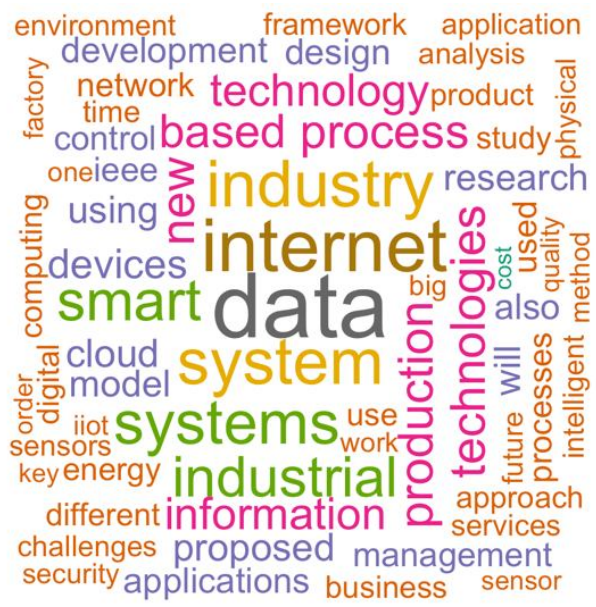

(b)

Figure 6: (a) A 1-gram word cloud of the keywords (b) A 1-gram word cloud of the abstracts

Figure 7 depicts the 2-gram word cloud of the abstract. The two most widely used words are "big data" and "cloud computing." According to research, IoT applications are poised to generate approximately 4.4 billion TB data by 2020. Comprehending this volume is not straightforward; moreover, the manual analysis of the data obtained using just one industrial sensor would take a lifetime. The count of connected devices is growing exponentially, and it is hardly a surprise that there will be over ten billion IoT sensors creating a massive volume of data by 2020. Additionally, these sensors and aspects of data like gathering, analysis, sharing, and transmission are real-time. Therefore, without data, these connected devices may not have the required functionality that warrants the immense attention these devices have received globally. Such IoT devices produce the data and use the cloud to store it. Furthermore, cloud computing scenarios will affect almost each element of production firms like how they control their operations, from financial management and enterprise resource planning (ERP) to workforce training and data analytics. Furthermore, the cloud is fundamental to how manufacturers assimilate themselves into industrial supply chains. This assertion is backed by the next set of prevalent words in the word cloud: supply chain. IoT is about to reform the supply chain with operational efficacies as well as revenue prospects. Currently, the supply chain is not concentrated on the individual sector but also on rival industry. Some examples of IoT for operational efficacies are vendor relations, asset tracking, forecasting and inventory, connected fleets, and schedule maintenance.

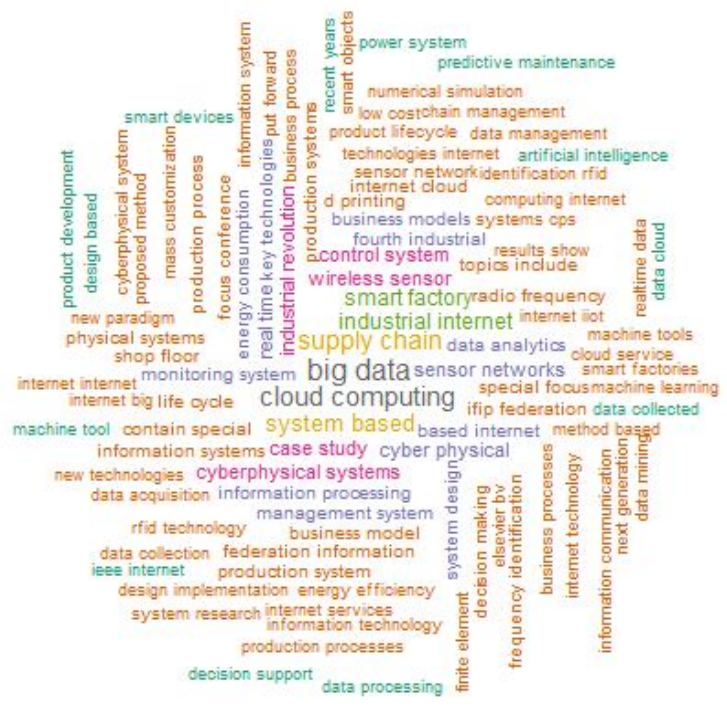

Figure 7: A 2-grams word cloud of the abstract in selected publications

Additional analyses are conducted employing the 3 -gram technique to ascertain the three most commonly used words in the abstracts of the publications. Table 2 lists such frequently used words. A majority of the publications specify the backbone of the IoT ecosystem, which is dependent on "wireless sensor networks" and "industrial internet iiot". IoT-specific use cases are expected to revolutionise manufacturing. The advancements in the IoT domain facilitate the swift and efficient transfer of information from automated or manual decision-making systems to the production equipment employed in smart factories. Sensors and physical devices establish an interconnect using the IoT framework backed by the internet, which may be connected using wired or wireless media.

"Cyber-physical systems" (CPS) is another commonly-used phrase. CPS comprises physical infrastructure integrated with modern computational and analytics frameworks [22][23]. Cyber-physical systems have been successfully applied in several domains like energy consumption, industrial automation, medical equipment, advanced military 
technology, among other domains [22][7][24][25]. Furthermore, CPS integration provides manufacturing processes to have self-awareness and perform maintenance with limited human intervention. Predictive analytics is an advanced analytics category, which, when integrated with the CPS ecosystem, facilitates the equipment to continuously self-monitor performance parameters and predict potential issues that may arise in the future. The combined use of decision support frameworks and analytics facilitates increased system uptime, enhanced efficiency, and better productivity in all aspects of the industrial use-case.

Table 2: The three most frequent words used in IoT application in manufacturing system

\begin{tabular}{|l|l|l|l|}
\hline Phrases & $\begin{array}{l}\text { Fre } \\
\mathrm{q}\end{array}$ & Phrases & Freq \\
\hline $\begin{array}{l}\text { wireless sensor } \\
\text { networks }\end{array}$ & 71 & big data analytics & 56 \\
\hline $\begin{array}{l}\text { cyber physical } \\
\text { systems }\end{array}$ & 60 & $\begin{array}{l}\text { supply chain } \\
\text { management }\end{array}$ & 27 \\
\hline $\begin{array}{l}\text { internet cloud } \\
\text { computing }\end{array}$ & 67 & $\begin{array}{l}\text { product lifecycle } \\
\text { management }\end{array}$ & 15 \\
\hline $\begin{array}{l}\text { radio frequency } \\
\text { identification }\end{array}$ & 56 & $\begin{array}{l}\text { enterprise resource } \\
\text { planning }\end{array}$ & 13 \\
\hline $\begin{array}{l}\text { fourth industrial } \\
\text { revolution }\end{array}$ & & \\
\hline
\end{tabular}

Figure 8 depicts the architecture used for CPS systems. Several engineering processes, like testing, optimisation, or design, have practical limits during actual use. CPS facilitates simulating a factory and its supply chain in real-time. Additionally, CPS helps create a plan that should be used for running the business as per the specific objectives. Fundamentally, such systems use the IoT ecosystem to send the required signals to the equipment at the appropriate time.

The virtualisation of the physical area of the premises and its synchronisation with the IoT cyberspace allows for a relatively easy and integrated understanding of the interactions and challenges because the human and mechanical systems are in the same domain, which is difficult to integrate otherwise. This heterogeneity has been challenging to manage. The homogenisation of these activities into one space enables integrated management. CPS is a software-based and a hybrid approach that uses software to emulate services and tangible products like equipment and sensors [13].

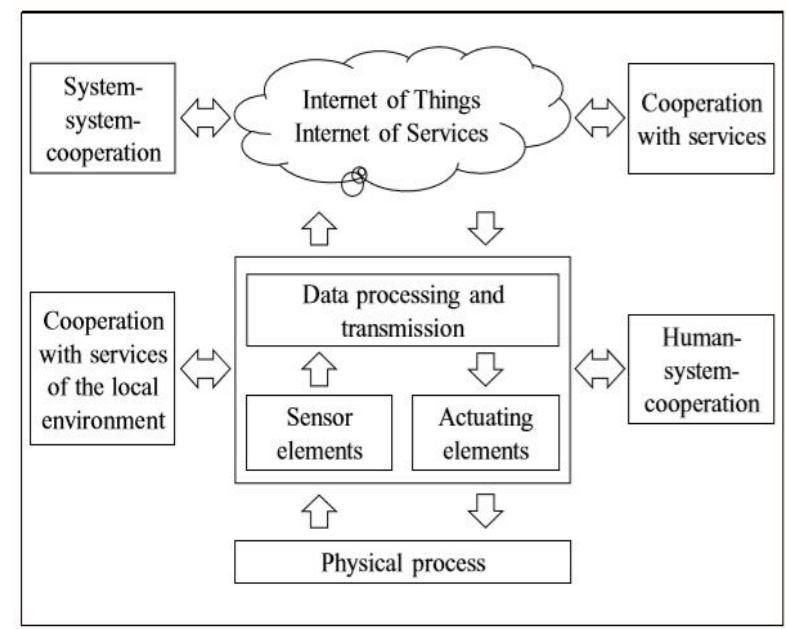

Figure 8: Structure of cyber-physical approach [13]

\subsection{Internet of Things (IoT)}

Essentially, IoT refers to an interconnection between real-world objects like vehicles, buildings, software, electronics, sensors, and many more to use some form of networking to establish a connection to exchange information. It is predicted that in the next five years, the number of connected devices is expected to reach 20 billion [26]. In manufacturing processes, the primary emphasis concerning IoT integration is to affix the equipment with sensors and networking ability. RFID stands for "Radiofrequency Identification," and is a significant communication technique used in the IoT space [27][28][29]. Typically, IoT equips the systems with sensors, RFID tags, cameras, actuators, and GPS-based location systems. All devices may gather, transmit, and receive data to facilitate an improved perspective concerning the production facilities. Figure 9 depicts the advantages of deploying an IoT-based platform for production facilities and associated operations. IoT application facilitates better visibility of operations through the supply chain while providing an opportunity to improve operational efficiency and contribute to the top line. Concerning operational efficiency, GPS sensors and RFID tags can help track the movement of the parts during manufacturing and the finished goods during storage and transport. Hence, IoT can help create an information exchange framework for manufacturing units that operates in real-time. Furthermore, the precision offered by IoT devices is superior to what a human can provide. For instance, Amazon manages its workflow using automated systems comprising Wi-Fi-enabled robots that scan QR codes to handle order management. The large amount of data obtained from these IoT sensors can help the company provide better quality control and facilitate smoother operations and forecast. In the context of production facilities, the implementation of smart sensing systems can help reduce downtime by better planning the 
maintenance processes, thereby positively affecting the revenue.

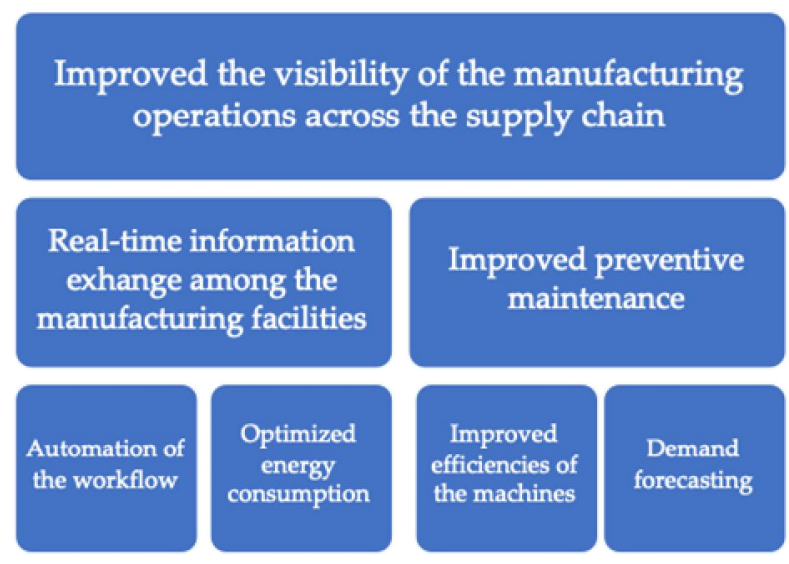

Figure 9: Benefit of using IOT framework in manufacturing operations

Table 3 specified the two commonly-used words in the publication that exemplifies the set of production activities that facilitate the IoT application for 571 papers. These top words employed for manufacturing represent its backbone. Smart production facilities, factories, and manufacturing activities have a common objective of optimising operations. Optimisation may comprise computer-based modelling, control, automation, use of big data to enhance efficiency. The National Institute of Standards and Technology (NIST) defines a manufacturing system as a "fully-integrated, collaborative manufacturing systems that respond in real-time to meet changing demands and conditions in the factory, in the supply network, and customer needs." Concerning manufacturing activity, IoT-based processes create business values through four primary domains, which are operating efficiency, supply chain management, predictive maintenance and inventory optimisation. The benefits of using IoT during manufacturing are illustrated using case studies, as specified in Table 4.

Table 3: Most two frequent words in the publications

\begin{tabular}{|l|l|c|}
\hline No & Phrases & Frequency \\
\hline 1 & manufacturing process/systems & 377 \\
\hline 2 & smart factory /manufacturing & 231 \\
\hline 3 & production systems & 176 \\
\hline 4 & manufacturing process & 160 \\
\hline 5 & Cyber-physical systems & 179 \\
\hline 6 & supply chain & 169 \\
\hline 7 & industrial revolution & 146 \\
\hline
\end{tabular}

\begin{tabular}{|l|l|l|}
8 & business model & 105 \\
\hline 9 & energy consumption & 99 \\
\hline 10 & life cycle & 98 \\
\hline
\end{tabular}

To aggregate the factory shop floor data, the IoT devices communicate with the cloud application in the production systems. In general, this data is generated by industrial equipment for additional actions; for instance, production plan optimisation [31]. The production system that was developed for the self-adaptation of the industrial equipment enables the human operator to enhance their productivity and minimise fatigue and stress [15]. Furthermore, the defect predictive manufacturing systems based on IoT emphasise on the automated production facilities, which facilitates prediction and response to the future situation [9]. Table 5 presents the state-of-the-art technologies employed in IoT for the manufacturing industry. It is evident from the table that the highest number of publications focuses on the connectivity for manufacturing applications. This is due to the fact that connectivity is the primary procedure in terms of IoT implementation in manufacturing operations. The data produced from the various IoT devices will not be recorded without the presence of a good connectivity between the devices.

Before the submission of a paper, the submitting author has the responsibility to garner agreement of all the co-authors and obtain the requisite consent of sponsors. Also, it is the responsibility and obligation of the authors to cite any relevant earlier work that was used for the study.

Table 4: Case study related to the IoT advantages in manufacturing process

\begin{tabular}{|c|c|c|}
\hline No & $\begin{array}{l}\text { IoT advantages } \\
\text { in } \\
\text { Manufacturing } \\
\text { Process }\end{array}$ & Case study \\
\hline 1 & $\begin{array}{l}\text { Supply Chain } \\
\text { Management }\end{array}$ & $\begin{array}{l}\text { Toyota : reduces recalls by } \\
\text { knowing exactly what machine } \\
\text { produce which components of } \\
\text { which vehicles[30]. } \\
\text { HP : integrates network analysis } \\
\text { and data visualization into its } \\
\text { supply chain management and } \\
\text { monitoring; has reduced the time } \\
\text { for supply chain management } \\
\text { projects by up to 50\%. } \\
\text { BMW : knows the real-time } \\
\text { status of all machines producing } \\
\text { all parts/components from all } \\
\text { suppliers going into vehicles [30] }\end{array}$ \\
\hline
\end{tabular}




\begin{tabular}{|c|c|c|}
\hline 2 & $\begin{array}{l}\text { Operating } \\
\text { Efficiency }\end{array}$ & $\begin{array}{l}\text { Ford: Placed sensors on virtually } \\
\text { every piece of production } \\
\text { equipment at its River Rouge } \\
\text { facility. } \\
\text { GM: Uses sensors to monitor } \\
\text { humidity conditions during } \\
\text { vehicle painting; if unfavorable, } \\
\text { the work piece is moved } \\
\text { elsewhere in plant or ventilation } \\
\text { systems adjusted. } \\
\text { Raytheon: Keeps track } \\
\text { of how many times a screw has } \\
\text { been turned in its factories. }\end{array}$ \\
\hline 3 & $\begin{array}{l}\text { Predictive } \\
\text { Maintenance }\end{array}$ & $\begin{array}{l}\text { Intel: Uses predictive modeling to } \\
\text { anticipate failures, prioritize } \\
\text { inspections, and cut monitoring } \\
\text { costs, save } \$ 3 \mathrm{M} \text {. } \\
\text { Ford: Downstream machines can } \\
\text { detect if work pieces they receive } \\
\text { are off in a particular minute } \\
\text { dimension, indicating possible } \\
\text { problems in upstream machines. } \\
\text { GE “Brilliant Factories” } \\
\text { initiative doubled production of } \\
\text { defectfree dishwashers and } \\
\text { washing machines. }\end{array}$ \\
\hline 4 & $\begin{array}{l}\text { Inventory } \\
\text { Optimization }\end{array}$ & $\begin{array}{l}\text { Wurth USA: Developed an " } \\
\text { iBins" system that uses } \\
\text { intelligent camera technology to } \\
\text { monitor the fill level of a supply } \\
\text { box and wirelessly transmit the } \\
\text { data to an inventory management } \\
\text { system that automatically } \\
\text { reorders supplies. }\end{array}$ \\
\hline
\end{tabular}

Table 5: Latest technologies used in IoT application in manufacturing industry

\begin{tabular}{|c|c|c|c|}
\hline No & Phrases & Method & Paper \\
\hline 1 & $\begin{array}{l}\text { Condition-b } \\
\text { ased } \\
\text { maintenance } \\
(\mathrm{CBM})\end{array}$ & $\begin{array}{l}\text { Map Reduce Framework } \\
\text { to increase computational } \\
\text { efficiency }\end{array}$ & [84] \\
\hline 2 & $\begin{array}{l}\text { Additively } \\
\text { manufacturi } \\
\text { ng }\end{array}$ & $\begin{array}{l}\text { 3D printed } \\
\text { Flexible and wearable } \\
\text { antenna systems } \\
\text { Adaptive control } \\
\text { UAV }\end{array}$ & $\begin{array}{l}{[85][86][87][88][} \\
89] \\
{[90]} \\
{[91]} \\
{[92]}\end{array}$ \\
\hline 3 & $\begin{array}{l}\text { Production } \\
\text { systems / } \\
\text { scheduling } \\
\end{array}$ & $\begin{array}{l}\text { Production progresses. } \\
\text { Micro-service based on }\end{array}$ & $\begin{array}{l}{[93][94][95][96][} \\
97][98][99] \\
{[100]}\end{array}$ \\
\hline
\end{tabular}

\begin{tabular}{|c|c|c|c|}
\hline & & $\begin{array}{l}\text { IoT } \\
\text { Customized production } \\
\text { environment } \\
\text { CNC machine } \\
\text { Logistic } \\
\text { Food manufacturing } \\
\text { Packaging technology } \\
\text { Planning/ scheduling } \\
\text { Optimization resources }\end{array}$ & $\begin{array}{l}{[101][102][38][1} \\
03] \\
{[104]} \\
{[105][18][106][1} \\
07] \\
{[108]} \\
{[109]} \\
{[110][17][111][1} \\
12][112][113] \\
{[114][115]}\end{array}$ \\
\hline 4 & $\begin{array}{l}\text { manufacturi } \\
\text { ng } \\
\text { maintenance } \\
\text { / monitoring }\end{array}$ & $\begin{array}{l}\text { Flexible thermoelectric } \\
\text { generators (TEGs) } \\
\text { Statistics pattern Analysis } \\
\text { (SPA) } \\
\text { Monitoring }\end{array}$ & $\begin{array}{l}{[116]} \\
{[71]} \\
{[117][118][119]}\end{array}$ \\
\hline 5 & $\begin{array}{l}\text { cyberphysic } \\
\text { al systems }\end{array}$ & $\begin{array}{l}\text { Industrial human-machine } \\
\text { collaboration. } \\
\text { Mitigating risk } \\
\text { Model driven engineering } \\
\text { Cyber physical } \\
\text { Digital manufacturing }\end{array}$ & $\begin{array}{l}{[15][22][120][12} \\
1] \\
{[122]} \\
{[16][123]} \\
{[124][23][125][1} \\
26][127][128][12 \\
9] \\
{[130]}\end{array}$ \\
\hline 6 & supply chain & $\begin{array}{l}\text { Servitization of } \\
\text { manufacturing } \\
\text { Activities }\end{array}$ & $\begin{array}{l}{[131]} \\
{[27][132][133][} \\
134]\end{array}$ \\
\hline 8 & $\begin{array}{l}\text { Predictive } \\
\text { Manufacturi } \\
\text { ng }\end{array}$ & $\begin{array}{l}\text { Optimized controller for a } \\
\text { specific task. } \\
\text { Vibration analysis }\end{array}$ & $\begin{array}{l}{[9][12][11]} \\
{[10]}\end{array}$ \\
\hline 9 & $\begin{array}{l}\text { energy } \\
\text { consumptio } \\
\mathrm{n}\end{array}$ & $\begin{array}{l}\text { Low power consumption } \\
\text { devices } \\
\text { Modeling }\end{array}$ & $\begin{array}{l}{[40][135]} \\
{[136][137]}\end{array}$ \\
\hline 10 & life cycle & $\begin{array}{l}\text { product lifecycle } \\
\text { management }\end{array}$ & {$[138][139][140]$} \\
\hline \multirow[t]{2}{*}{13} & Monitoring & $\begin{array}{l}\text { Integrated power saving } \\
\text { wireless network for } \\
\text { monitoring factory } \\
\text { operations. } \\
\text { Industrial emission } \\
\text { monitoring system }\end{array}$ & $\begin{array}{l}{[41]} \\
{[141]}\end{array}$ \\
\hline & & $\begin{array}{l}\text { An integrated vision for } \\
\text { fashion industry }\end{array}$ & [142] \\
\hline 14 & $\begin{array}{l}\text { Quality } \\
\text { Control }\end{array}$ & Automotive industry & {$[143][144][145]$} \\
\hline 15 & Sustainable & $\begin{array}{l}\text { Material handling } \\
\text { Green technology }\end{array}$ & $\begin{array}{l}{[146]} \\
{[147]}\end{array}$ \\
\hline
\end{tabular}

The upcoming IoT-based manufacturing operations are likely to transform the human operator into "cyber-operator" and the machine tools into "cyber-machine tools", thereby enabling the production of high value, volume, variety, veracity, and velocity of data. The data generated from the manufacturing operations comprised unstructured and structured data. Data plays a significant role in resolving a problem in real-time and minimising the cost incurred for delayed response to the problem.

\section{CONCLUSION}

In the recent decade, the design and implementation of the manufacturing system have been influenced by the evolution of the IoT applications. IoT applications play an important role in data gathering. On the other hand, 
data analytics is used to convert the information into insights, which in turn can be used to mitigate the challenges faced by the companies. The IoT applications, when integrated with the manufacturing systems, are capable of enhancing operations through the linking of cyber and physical capabilities, utilisation of information and analytics, and leveraging the big data evolution. It is now more than ever that the manufacturing companies are compelled to consider adapting their business models dynamically so as to keep up with the global competition and growing market demands. The companies that have the potential to gather all the significant data can eventually use the data to analyse the existing state of their processes and identify the process that will enable the most optimum progress and keep them ahead of their competition. Additionally, the manufacturing operations can be successfully streamlined through decisive and actionable insights to improve the production line continuously.

This study is primarily exploratory in its scope and approach. Text analytics was applied in this study to demonstrate its significance and value in generating and codifying rich, effective and quality knowledge that enables the researchers of this field to gain insights about the present research. Apart from its many contributions, the study comes with its set of limitations, which could serve as opportunities for future research. Text analytics was applied only on the articles that were published in Scopus publications, over a course of five years. The future research can further apply text analytics over longer periods and with more sources to assess the trends and arrive at robust findings. The various sources of unstructured data, for example, data from social media feed, websites, and other user generated content available on the Web, have the potential to generate valuable insights.

\section{ACKNOWLEDGEMENT}

The authors express their deepest gratitude to Universiti Teknikal Malaysia Melaka (UTeM) for supporting this research PJP/2019/FTMK(68)/S01678.

\section{REFERENCES}

1. GrowthEnabler, "Discover Key Trends \& Insights on Disruptive Technologies \& IoT innovations," Mark. Pulse Report, Internet Things, no. April, 2017.

2. X. V. Wang and L. Wang, "A cloud-based production system for information and service integration: an internet of things case study on waste electronics," Enterp. Inf. Syst., vol. 11, no. 7, pp. 952-968, 2017.
3. H. Jo, S. Kang, H. J. Kwon, and J. D. Lee, "In-door location-based smart factory cloud platform supporting device-to-device self-collaboration," in 2017 IEEE International Conference on Big Data and Smart Computing, BigComp 2017, 2017, pp. 348-351.

4. J. Wan, S. Tang, Q. Hua, D. Li, C. Liu, and J. Lloret, "Context-Aware Cloud Robotics for Material Handling in Cognitive Industrial Internet of Things," IEEE Internet Things J., 2017.

5. C. Yang, S. Lan, W. Shen, G. Q. Huang, X. Wang, and T. Lin, "Towards product customization and personalization in IoT-enabled cloud manufacturing," Cluster Comput., vol. 20, no. 2, pp. 1717-1730, 2017. https://doi.org/10.1007/s10586-017-0767-x

6. R. Dou and G. Nan, "Optimizing sensor network coverage and regional connectivity in industrial IoT systems," IEEE Syst. J., vol. 11, no. 3, pp. 1351-1360, 2017.

7. R. Silva, J. Reis, L. Neto, and G. Goncalves, "Universal parser for wireless sensor networks in industrial cyber physical production systems," in Proceedings - 2017 IEEE 15th International Conference on Industrial Informatics, INDIN 2017, 2017, pp. 633-638.

8. T. Hasegawa, "International standardization and its applications in industrial wireless network to realize smart manufacturing," in 2017 56th Annual Conference of the Society of Instrument and Control Engineers of Japan, SICE 2017, 2017, vol. 2017-Novem, pp. 275-278.

9. Y. J. Kwon and D. H. Kim, "IoT-based defect predictive manufacturing systems," in International Conference on Information and Communication Technology Convergence: ICT Convergence Technologies Leading the Fourth Industrial Revolution, ICTC 2017, 2017, vol. 2017-Decem, pp. 1067-1069.

10. D. Jung, Z. Zhang, and M. Winslett, "Vibration analysis for iot enabled predictive maintenance," in Proceedings - International Conference on Data Engineering, 2017, pp. 1271-1282.

11. S. T. March and G. D. Scudder, "Predictive maintenance: strategic use of IT in manufacturing organizations," Inf. Syst. Front., pp. 1-15, 2017.

12. R. C. Parpala and R. Iacob, "Application of IoT concept on predictive maintenance of industrial equipment," in MATEC Web of Conferences, 2017, vol. 121.

13. M. Mikusz, "Towards an understanding of cyber-physical systems as industrial software-product-service systems," Procedia CIRP, vol. 16, pp. 385-389, 2014.

14. J. Shi, "A Survey of Cyber-Physical Systems," 2011. 
15. J. Reis, R. Pinto, and G. Goncalves, "Human-centered application using cyber-physical production system," in Proceedings IECON 2017 43rd Annual Conference of the IEEE Industrial Electronics Society, 2017, vol. 2017-Janua, pp. 8634-8639.

16. K. Thramboulidis, P. Bochalis, and J. Bouloumpasis, "A framework for MDE of IoT-based manufacturing cyber-physical systems," in ACM International Conference Proceeding Series, 2017. https://doi.org/10.1145/3131542.3131554

17. W. Ge and R. Zhong, "A case of big data analytics for an internet of things manufacturing shop floor," in Proceedings of International Conference on Computers and Industrial Engineering, CIE, 2017.

18. R. Y. Zhong, C. Xu, C. Chen, and G. Q. Huang, "Big Data Analytics for Physical Internet-based intelligent manufacturing shop floors," Int. J. Prod. Res., vol. 55, no. 9, pp. 2610-2621, 2017.

19. D. Tranfield, D. Denyer, and P. Smart, "Towards a Methodology for Developing Evidence-Informed Management Knowledge by Means of Systematic Review," Br. J. Manag., vol. 14, no. 3, pp. 207-222, 2003.

20. F. Haneem, R. Ali, N. Kama, and S. Basri, "Descriptive analysis and text analysis in Systematic Literature Review: A review of Master Data Management," 2017 Int. Conf. Res. Innov. Inf. Syst., pp. 1-6, 2017.

21. L. Jure, R. Anand, and U. Jeffrey david, Mining of Massive Datasets. 2014.

22. X. Yao, J. Zhou, Y. Lin, Y. Li, H. Yu, and Y. Liu, "Smart manufacturing based on cyber-physical systems and beyond," J. Intell. Manuf., pp. 1-13, 2017.

23. J. Cecil, S. Albuhamood, A. Cecil-Xavier, and P. Ramanathan, "An Advanced Cyber Physical Framework for Micro Devices Assembly," IEEE Trans. Syst. Man, Cybern. Syst., 2017.

24. S. M. N. A. Sunny, X. F. Liu, and M. R. Shahriar, "MTComm: A semantic ontology based internet scale communication method of manufacturing services in a cyber-physical manufacturing cloud," in Proceedings - 2017 IEEE 2nd International Congress on Internet of Things, ICIOT 2017, 2017, pp. 121-128.

25. C.-C. Chen, C.-L. Chen, C.-Y. Ciou, and J.-X. Liu, "Communication scheduling scheme based on big-data regression analysis and genetic algorithm for cyber-physical factory automation," in 2016 IEEE International Conference on Systems, Man, and Cybernetics, SMC 2016 - Conference Proceedings, 2017, pp. 2603-2608.

26. Gatner, "IT Glossary," 2014. .

27. M. Chamekh, S. El Asmi, M. Hamdi, and T.-H. Kim, "Context aware middleware for RFID based pharmaceutical supply chain," in 2017 13th International Wireless Communications and Mobile Computing Conference, IWCMC 2017, 2017, pp. 1915-1920.

28. S. Huang, Y. Guo, S. Zha, F. Wang, and W. Fang, "A Real-time Location System Based on RFID and UWB for Digital Manufacturing Workshop," in Procedia CIRP, 2017, vol. 63, pp. 132-137.

29. T. Kamigaki, "Object-oriented RFID with IoT: A design concept of information systems in manufacturing," Electron., vol. 6, no. 1, 2017.

30. M. Borja Ramis, Ferrer Lastra Wael M., C. Enbo, and L. M. Jose, "Connecting web-based IoT devices to a cloud-based manufacturing platform," in 43rd Annual Conference of the IEEEIndustrial Electronics Society, IECON 2017, 2017.

31. B. R. Ferrer, W. M. Mohammed, E. Chen, and J. L. M. Lastra, "Connecting web-based IoT devices to a cloud-based manufacturing platform," in Proceedings IECON 2017 - 43rd Annual Conference of the IEEE Industrial Electronics Society, 2017, vol. 2017-Janua, pp. 8628-8633.

32. H. P. Breivold, "Internet-of-Things and Cloud Computing for Smart Industry: A Systematic Mapping Study," in Proceedings - 2017 5th International Conference on Enterprise Systems: Industrial Digitalization by Enterprise Systems, ES 2017, 2017, pp. 299-304. https://doi.org/10.1109/ES.2017.56

33. X. Xu, A. Nieto, B. R. Ferrer, R. Camp, and J. L. M. Lastra, "Cloud based solution enabling collaborative supply network optimization for an original equipment manufacturer," in IEEE International Conference on Industrial Informatics (INDIN), 2017, pp. 689-694.

34. R. Y. Zhong, L. Wang, and X. Xu, "An IoT-enabled Real-time Machine Status Monitoring Approach for Cloud Manufacturing," in Procedia CIRP, 2017, vol. 63, pp. 709-714.

35. Y. Hao and P. Helo, "The role of wearable devices in meeting the needs of cloud manufacturing: A case study," Robot. Comput. Integr. Manuf., vol. 45, pp. 168-179, 2017.

36. J. Shen et al., "Interactive UHF/UWB RFID tag for mass customization," Inf. Syst. Front., vol. 19, no. 5, pp. 1177-1190, 2017.

37. Y. Chen, G. Q. Huang, W. Shen, T. Lin, W. Xianbin, and S. Lan, "Open and collaborative product design and production in IoT-enabled manufacturing cloud," in 2016 IEEE International Conference on Systems, Man, and Cybernetics, SMC 2016 - Conference Proceedings, 2017, pp. 4124-4129.

38. S. Suginouchi, D. Kokuryo, and T. Kaihara, "Value Co-creative Manufacturing System for Mass Customization: Concept of Smart Factory and Operation Method Using Autonomous Negotiation 
Mechanism," in Procedia CIRP, 2017, vol. 63, pp. 727-732.

39. H. Lee, "Framework and development of fault detection classification using IoT device and cloud environment," J. Manuf. Syst., vol. 43, pp. 257-270, 2017.

40. T. Watanabe, "Current status and prospect for EUV lithography," in Proceedings of 2017 7th International Conference on Integrated Circuits, Design, and Verification, ICDV 2017, 2017, vol. 2017-Decem, pp. 2-7.

41. H. Minh Vo, "Online working condition monitoring system integrated power saving and security using zigbee wireless sensor network," in International Conference on Advanced Technologies for Communications, 2017, vol. 2017-Octob, pp. 140-143.

42. N.-N. Dao, Y. Lee, S. Cho, E. Kim, K.-S. Chung, and C. Keum, "Multi-tier multi-access edge computing: The role for the fourth industrial revolution," in International Conference on Information and Communication Technology Convergence: ICT Convergence Technologies Leading the Fourth Industrial Revolution, ICTC 2017, 2017, vol. 2017-Decem, pp. 1280-1282.

43. D. B. Rawat, M. S. Parwez, and A. Alshammari, "Edge Computing Enabled Resilient Wireless Network Virtualization for Internet of Things," in Proceedings - 2017 IEEE 3rd International Conference on Collaboration and Internet Computing, CIC 2017, 2017, vol. 2017-Janua, pp. 155-162.

https://doi.org/10.1109/CIC.2017.00030

44. M. Zhao et al., "Verification and validation framework for $5 \mathrm{~g}$ network services and apps," in 2017 IEEE Conference on Network Function Virtualization and Software Defined Networks, NFV-SDN 2017, 2017, vol. 2017-Janua, pp. 321-326.

45. Z. Meng, Z. Wu, and J. Gray, "A collaboration-oriented M2M messaging mechanism for the collaborative automation between machines in future industrial networks," Sensors (Switzerland), vol. 17, no. 11, 2017.

46. L. Kim-Hung, S. K. Datta, C. Bonnet, F. Hamon, and A. Boudonne, "An industrial IoT framework to simplify connection process using system-generated connector," in RTSI 2017 - IEEE 3rd International Forum on Research and Technologies for Society and Industry, Conference Proceedings, 2017.

47. Z. Wu, Z. Meng, and J. Gray, "IoT-Based Techniques for Online M2M-Interactive Itemized Data Registration and Offline Information Traceability in a Digital Manufacturing System," IEEE Trans. Ind. Informatics, vol. 13, no. 5, pp. 2397-2405, 2017.
48. H. Chen, Y. Zhu, and J. Wu, "Design RFCS with LonWorks technology in internet of things manufacturing," in 2016 3rd Smart Cloud Networks and Systems, SCNS 2016, 2017.

49. P. Marcon et al., "Communication technology for industry 4.0," in Progress in Electromagnetics Research Symposium, 2017, pp. 1694-1697.

50. M. Liu, J. Ma, L. Lin, M. Ge, Q. Wang, and C. Liu, "Intelligent assembly system for mechanical products and key technology based on internet of things," J. Intell. Manuf., vol. 28, no. 2, pp. 271-299, 2017.

51. G. P. Dave, N. Sureshkumar, and S. S. Blessy Trencia Lincy, "Performance evaluation of throughput computing workloads using multi-core processors and graphics processors," in IOP Conference Series: Materials Science and Engineering, 2017, vol. 263, no. 4.

52. V. P. Yanambaka, S. P. Mohanty, and E. Kougianos, "Making use of semiconductor manufacturing process variations: FinFET-based physical unclonable functions for efficient security integration in the IoT," Analog Integr. Circuits Signal Process., vol. 93, no. 3, pp. 429-441, 2017.

53. N. Voinov, I. Chernorutsky, P. Drobintsev, and V. Kotlyarov, "An approach to net-centric control automation of technological processes within industrial IoT systems," Adv. Manuf., vol. 5, no. 4, pp. 388-393, 2017.

54. O. Jaradat, I. Sljivo, I. Habli, and R. Hawkins, "Challenges of Safety Assurance for Industry 4.0," in Proceedings - 2017 13th European Dependable Computing Conference, EDCC 2017, 2017, pp. 103-106.

55. K.-S. Wong and M. H. Kim, "Privacy protection for data-driven smart manufacturing systems," Int. J. Web Serv. Res., vol. 14, no. 3, pp. 17-32, 2017.

56. S. Tedeschi, J. Mehnen, and R. Roy, "IoT security hardware framework for remote maintenance of legacy machine tools," in ACM International Conference Proceeding Series, 2017.

57. A. Riel, C. Kreiner, G. Macher, and R. Messnarz, "Integrated design for tackling safety and security challenges of smart products and digital manufacturing," CIRP Ann. - Manuf. Technol., vol. 66, no. 1, pp. 177-180, 2017.

58. N. Sohrabi Safa, C. Maple, and T. Watson, "An information security risk management model for smart industries," in Advances in Transdisciplinary Engineering, 2017, vol. 6, pp. 257-262.

59. G. Palavicini, J. Bryan, E. Sheets, M. Kline, and J. S. Miguel, "Towards firmware analysis of industrial internet of things (IIoT): Applying symbolic analysis to IIoT firmware vetting," in IoTBDS 2017 - Proceedings of the 2nd International Conference on Internet of Things, Big Data and Security, 2017, pp. 470-477. 
https://doi.org/10.5220/0006393704700477

60. T. Pereira, L. Barreto, and A. Amaral, "Network and information security challenges within Industry 4.0 paradigm," Procedia Manuf., vol. 13, pp. 1253-1260, 2017.

61. S. G. Pease, P. P. Conway, and A. A. West, "Hybrid ToF and RSSI real-time semantic tracking with an adaptive industrial internet of things architecture," J. Netw. Comput. Appl., vol. 99, pp. 98-109, 2017.

62. S. Kamada and T. Ichimura, "Knowledge extracted from recurrent deep belief network for real time deterministic control," in 2017 IEEE International Conference on Systems, Man, and Cybernetics, SMC 2017, 2017, vol. 2017-Janua, pp. 825-830.

63. T. Peng and P. Jinqi, "A Recommendation System for Collaborative Visualization Platforms," in Proceedings - 2017 5th International Conference on Enterprise Systems: Industrial Digitalization by Enterprise Systems, ES 2017, 2017, pp. 58-61.

64. C. Jun, J. Y. Lee, J.-S. Yoon, and B. H. Kim, “Applications' Integration and Operation Platform to Support Smart Manufacturing by Small and Medium-sized Enterprises," Procedia Manuf., vol. 11, pp. 1950-1957, 2017.

65. D. Moldovan, T. Cioara, I. Anghel, and I. Salomie, "Machine learning for sensor-based manufacturing processes," in Proceedings - 2017 IEEE 13th International Conference on Intelligent Computer Communication and Processing, ICCP 2017, 2017, pp. $147-154$.

66. C. Ciufudean and C. Buzduga, Modelling the diagnosis of industry internet of things, vol. 738 . 2017.

67. J. Cecil, S. Albuhamood, and A. Gupta, "A Virtual Reality based Internet-of-Things (IoT) framework for micro devices assembly," in Proceedings of the ACM Symposium on Virtual Reality Software and Technology, VRST, 2017, vol. Part F1319.

68. H. Hatam, F. A. Aziz, W. Z. Wan Hasan, and M. K. A. Mohd Ariffina, "Real time wireless monitoring and controlling of 3-D single point incremental tool," J. Comput. Theor. Nanosci., vol. 14, no. 9, pp. 4586-4596, 2017.

69. R. Krishnamurthy, J. Cecil, and D. Perera, "An Internet-of-Things based framework for collaborative manufacturing," in ASME International Mechanical Engineering Congress and Exposition, Proceedings (IMECE), 2017, vol. 2.

70. C. Alexakos, C. Anagnostopoulos, and A. P. Kalogeras, "Integrating IoT to manufacturing processes utilizing semantics," in IEEE International Conference on Industrial Informatics (INDIN), 2017, pp. 154-159.

71. Q. P. He and J. Wang, "Statistical process monitoring as a big data analytics tool for smart manufacturing," J. Process Control, 2017.
72. J. I. R. Molano, L. E. C. Bravo, and E. R. L. Santana, Data architecture for the internet of things and industry 4.0, vol. 10387 LNCS. 2017.

73. P. Eirinakis et al., A proposal of decentralised architecture for optimised operations in manufacturing ecosystem collaboration, vol. 506. 2017.

74. C.-F. Chien, T.-Y. Hong, and H.-Z. Guo, "A Conceptual Framework for 'Industry 3.5' to Empower Intelligent Manufacturing and Case Studies," Procedia Manuf., vol. 11, pp. 2009-2017, 2017. https://doi.org/10.1016/j.promfg.2017.07.352

75. S. Eruvankai, M. Muthukrishnan, and A. K. Mysore, "Accelerating IIOT adoption with OPC UA," Internetworking Indones. J., vol. 9, no. 1, pp. 3-8, 2017.

76. H. Sasajima, "Function blocks to realize connection of any devices all over the plant," in 2017 56th Annual Conference of the Society of Instrument and Control Engineers of Japan, SICE 2017, 2017, vol. 2017-Novem, pp. 267-272.

77. O. Miki and K. Hideki, "NEC industrial IoT — For manufacturing in the age of IoT," NEC Tech. J., vol. 12, no. 1, pp. 36-39, 2017.

78. A. J. C. Trappey, C. V. Trappey, U. Hareesh Govindarajan, A. C. Chuang, and J. J. Sun, “A review of essential standards and patent landscapes for the Internet of Things: A key enabler for Industry 4.0," Adv. Eng. Informatics, vol. 33, pp. 208-229, 2017.

79. F. Tao and Q. Qi, "New IT Driven Service-Oriented Smart Manufacturing: Framework and Characteristics," IEEE Trans. Syst. Man, Cybern. Syst., 2017.

80. [G. Hwang, J. Lee, J. Park, and T.-W. Chang, "Developing performance measurement system for Internet of Things and smart factory environment," Int. J. Prod. Res., vol. 55, no. 9, pp. 2590-2602, 2017.

81. A. Konapala and R. Koona, "An open and web-based StepNC manufacturing system (OW-StepNC)," Int. J. Internet Manuf. Serv., vol. 4, no. 3, pp. 195-221, 2017.

82. Deloitte, "Analytics for Manufacturers," pp. 1-11, 2013.

83. Oracle, "Improving Manufacturing Performance with Big Data Architect's Guide and Reference Architecture Introduction," Oracle Corp., no. April, 2015.

84. C. Lin, L. Shu, D. Deng, T. Yeh, Y. Chen, and H. Hsieh, "A MapReduce-Based Ensemble Learning Method with Multiple Classifier Types and Diversity for Condition-based Maintenance with Concept Drifts," IEEE Cloud Computing, 2017.

85. C. Casarini, J. F. C. Windmill, and J. C. Jackson, "3D printed small-scale acoustic metamaterials 
based on Helmholtz resonators with tuned overtones," in Proceedings of IEEE Sensors, 2017, vol. 2017-Decem, pp. 1-3.

86. C. Tomassoni and M. Bozzi, "Substrate integrated waveguide cavity filters: Miniaturization and new materials for IoT applications," Radioengineering, vol. 26, no. 3, pp. 633-641, 2017.

87. T. Tiedje, S. Lungen, M. Schubert, M. Luniak, K. Nieweglowski, and K. Bock, "Will Low-Cost 3D Additive Manufactured Packaging Replace the Fan-Out Wafer Level Packages?," in Proceedings Electronic Components and Technology Conference, 2017, pp. 1065-1070.

88. N. Do, "Integration of design and manufacturing data to support personal manufacturing based on 3D printing services," Int. J. Adv. Manuf. Technol., vol. 90, no. 9-12, pp. 3761-3773, 2017.

89. F. Salamone, L. Danza, I. Meroni, and M. Pollastro, "A low-cost environmental monitoring system: How to prevent systematic errors in the design phase through the combined use of additive manufacturing and thermographic techniques," Sensors (Switzerland), vol. 17, no. 4, 2017.

90. A. Shamim, "3D inkjet printed flexible and wearable antenna systems," in 2017 International Symposium on Antennas and Propagation, ISAP 2017, 2017, vol. 2017-Janua, pp. 1-2.

91. P. D. Drobintsev, V. P. Kotlyarov, I. G. Chernorutsky, L. P. Kotlyarova, and O. V. Aleksandrova, "Approach to adaptive control of technological manufacturing processes of IoT metalworking workshop," in Proceedings of 2017 20th IEEE International Conference on Soft Computing and Measurements, SCM 2017, 2017, pp. 174-176.

92. A. Brom, E. Gorlacheva, and I. Pekshev, "The perspectives of additive manufacturing technologies implementation in mass production of short range unmanned aerial vehicle," in 2017 International Conference on Mechanical, System and Control Engineering, ICMSC 2017, 2017, pp. 27-30.

93. P. Lin, M. Li, X. Kong, J. Chen, G. Q. Huang, and M. Wang, "Synchronisation for smart factory towards IoT-enabled mechanisms," Int. J. Comput. Integr. Manuf., pp. 1-12, 2017.

94. B. Chen, S.-Y. Tsai, and J.-Y. J. Chang, "Development of intelligent coil leveling machine for smart manufacturing," in M2VIP 2016 Proceedings of 23rd International Conference on Mechatronics and Machine Vision in Practice, 2017.

95. M. Nakamura, S. Makihara, J.-I. Sugiura, and Y. Kamioka, "Dynamic optimization production system based on simulation integrated manufacturing and its application to mass production," Int. J. Autom. Technol., vol. 11, no. 1, pp. 56-66, 2017.

96. C. Wang, P. Jiang, and T. Lu, "Production events graphical deduction model enabled real-time production control system for smart job shop," Proc. Inst. Mech. Eng. Part C J. Mech. Eng. Sci., 2017.

97. F. Gregori, A. Papetti, M. Pandolfi, M. Peruzzini, and M. Germani, "Digital Manufacturing Systems: A Framework to Improve Social Sustainability of a Production Site," in Procedia CIRP, 2017, vol. 63, pp. 436-442.

98. M. Maeda, Y. Sakurai, T. Tamaki, and Y. Nonaka, "Method for Automatically Recognizing Various Operation Statuses of Legacy Machines," in Procedia CIRP, 2017, vol. 63, pp. 418-423.

99. H. Lee, K. Ryu, and Y. Cho, "A Framework of a Smart Injection Molding System Based on Real-time Data," Procedia Manuf., vol. 11, pp. 1004-1011, 2017.

100.C. K. M. Lee, S. Z. Zhang, and K. K. H. Ng, "Development of an industrial Internet of things suite for smart factory towards re-industrialization," Adv. Manuf., vol. 5, no. 4, pp. 335-343, 2017. https://doi.org/10.1109/CADIAG.2017.8075699

101.D. Kokuryo, T. Kaihara, S. Suginouchi, and S. Kuik, "A study on value co-creative design and manufacturing system for tailor-made rubber shoes production - Construction of value co-creative smart factory," in International Symposium on Flexible Automation, ISFA 2016, 2016, pp. 171-174.

102.B. Lin, G. Wang, Z. Chen, and B. Lin, "Intelligent manufacturing executing system of heat treatment based on internet of things," Jinshu Rechuli/Heat Treat. Met., vol. 42, no. 3, pp. 195-197, 2017.

103.[C. Y. Leong and I. Koshijima, "Internet of things (IoT) for dynamic change management in mass customization," in CEUR Workshop Proceedings, 2017, vol. 2063.

104.I. R. K. Al-Saedi, F. M. Mohammed, and S. S. Obayes, "CNC machine based on embedded wireless and Internet of Things for workshop development," in 2017 International Conference on Control, Automation and Diagnosis, ICCAD 2017, 2017, pp. 439-444.

105.A. J. C. Trappey, C. V. Trappey, C.-Y. Fan, A. P. T. Hsu, X.-K. Li, and I. J. Y. Lee, "IoT patent roadmap for smart logistic service provision in the context of Industry 4.0," J. Chinese Inst. Eng. Trans. Chinese Inst. Eng. A/Chung-kuo K. Ch'eng Hsuch K'an, vol. 40, no. 7, pp. 593-602, 2017.

106.B. Mahmud, "Internet of things (IoT) for manufacturing logistics on SAP ERP applications," J. Telecommun. Electron. Comput. Eng., vol. 9, no. 2-6, pp. 43-47, 2017. 
107.X. Liu, J. Pei, L. Liu, H. Cheng, M. Zhou, and P. M. Pardalos, Hybrid Manufacturing Distributed Inventory Management with Sharing Logistics, vol. 126. 2017.

108.R. Dolci, "IoT Solutions for Precision Farming and Food Manufacturing: Artificial Intelligence Applications in Digital Food," in Proceedings International Computer Software and Applications Conference, 2017, vol. 2, pp. 384-385.

109.S. Kroehnert, J. Campos, A. Cardoso, E. O’Toole, and A. Janeiro, "WLFO packaging technologybased WLSiP -enabler for packaging of ioT/ioE modules," Adv. Microelectron., vol. 44, no. 3, pp. 6-10, 2017.

110.K. A. Kurniadi and K. Ryu, "Development of IOT-based Reconfigurable Manufacturing System to solve Reconfiguration Planning Problem," Procedia Manuf., vol. 11, pp. 965-972, 2017.

111.H. Zhu, Y. Wang, and M. Chen, "Research on mechanism of real-time mas based dynamic intelligent manufacturing systems," Mechanika, vol. 24, no. 1, pp. 121-127, 2017.

112.G. Guizzi, S. Vespoli, and S. Santini, "On the architecture scheduling problem of Industry 4.0," in CEUR Workshop Proceedings, 2017, vol. 2010, pp. 94-100.

113.C. Reuter, F. Brambring, T. Hempel, and P. Kopp, "Benefit Oriented Production Data Acquisition for the Production Planning and Control," in Procedia CIRP, 2017, vol. 61, pp. 487-492.

114.A. R. Netom, M. F. G. Ribeiro, G. G. Cunha, and L. Landau, "The industrial internet of things and technological innovation in its applications for resources optimisation," Int. J. Simul. Process Model., vol. 12, no. 6, pp. 525-534, 2017.

115.L. P. Steenkamp, D. Hagedorn-Hansen, and G. A. Oosthuizen, "Visual Management System to Manage Manufacturing Resources," Procedia Manuf., vol. 8, pp. 455-462, 2017.

116.B. Iezzi, K. Ankireddy, J. Twiddy, M. D. Losego, and J. S. Jur, "Printed, metallic thermoelectric generators integrated with pipe insulation for powering wireless sensors," Appl. Energy, vol. 208, pp. 758-765, 2017.

117.I.-L. Yen, S. Zhang, F. Bastani, and Y. Zhang, “A Framework for IoT-Based Monitoring and Diagnosis of Manufacturing Systems," in Proceedings - 11th IEEE International Symposium on Service-Oriented System Engineering, SOSE 2017, 2017, pp. 1-8.

118.W. Li and S. Kara, "Methodology for Monitoring Manufacturing Environment by Using Wireless Sensor Networks (WSN) and the Internet of Things (IoT)," in Procedia CIRP, 2017, vol. 61, pp. 323-328.

119.S. Tedeschi, C. Emmanouilidis, M. Farnsworth, J. Mehnen, and R. Roy, New Threats for Old Manufacturing Problems: Secure IoT-Enabled
Monitoring of Legacy Production Machinery, vol. 513. 2017.

120.A. Goudo, "ICT-based monozukuri innovation activities and practice of human-machine harmonized production," Fujitsu Sci. Tech. J., vol. 53, no. 4, pp. 77-83, 2017.

121.A. Ito, K. Takizawa, and A. Miyazawa, "Fujitsu's Monozukuri strategy," Fujitsu Sci. Tech. J., vol. 53, no. 4, pp. 10-21, 2017.

122.D. Bogataj, M. Bogataj, and D. Hudoklin, "Mitigating risks of perishable products in the cyber-physical systems based on the extended MRP model," Int. J. Prod. Econ., vol. 193, pp. 51-62, 2017.

123.H. Khaleel et al., "Heterogeneous applications, tools, and methodologies in the car manufacturing industry through an IoT approach," IEEE Syst. J., vol. 11, no. 3, pp. 1412-1423, 2017.

124.W. Jin, Z. Liu, Z. Shi, C. Jin, and J. Lee, "CPS-enabled worry-free industrial applications," in 2017 Prognostics and System Health Management Conference, PHM-Harbin 2017 Proceedings, 2017.

125.E. Marilungo, A. Papetti, M. Germani, and M. Peruzzini, "From PSS to CPS Design: A Real Industrial Use Case Toward Industry 4.0," in Procedia CIRP, 2017, vol. 64, pp. 357-362.

126.S. Kim and S. Park, "CPS(Cyber Physical System) based Manufacturing System Optimization," in Procedia Computer Science, 2017, vol. 122, pp. 518-524.

127.S. Choi, G. Kang, C. Jun, J. Y. Lee, and S. Han, "Cyber-physical systems: A case study of development for manufacturing industry," Int. J. Comput. Appl. Technol., vol. 55, no. 4, pp. 289-297, 2017.

128.C. Liu and X. Xu, "Cyber-physical Machine Tool The Era of Machine Tool 4.0," in Procedia CIRP, 2017, vol. 63, pp. 70-75.

129.Z. Jakovljevic, V. Majstorovic, S. Stojadinovic, S. Zivkovic, N. Gligorijevic, and M. Pajic, Cyber-physical manufacturing systems (CPMS). 2017.

130.A. J. Isaksson, I. Harjunkoski, and G. Sand, "The impact of digitalization on the future of control and operations," Comput. Chem. Eng., 2017.

131.A. Rymaszewska, P. Helo, and A. Gunasekaran, "IoT powered servitization of manufacturing - an exploratory case study," Int. J. Prod. Econ., vol. 192, pp. 92-105, 2017.

132.X. Liu, J. Pei, L. Liu, H. Cheng, M. Zhou, and P. M. Pardalos, Dynamic Coordinated Supply Chain Scheduling in an IoT Environment, vol. 126. 2017.

133.D. Bogataj, M. Bogataj, and D. Hudoklin, "Reprint of 'Mitigating risks of perishable products in the cyber-physical systems based on the extended MRP model,", Int. J. Prod. Econ., 2017. 
134.Makmur , Maria T. V. , Gunawan W. "The Application of Big Data Analytics in Supply Planning", International Journal of Advanced Trends in Computer Science and Engineering, vol 9, no 1, 2020. https://doi.org/10.30534/ijatcse/2020/84912020

135. Y. Li, Z. Sun, L. Han, and N. Mei, "Fuzzy Comprehensive Evaluation Method for Energy Management Systems Based on an Internet of Things," IEEE Access, vol. 5, pp. 21312-21322, 2017.

136.J. Qin, Y. Liu, and R. Grosvenor, “A Framework of Energy Consumption Modelling for Additive Manufacturing Using Internet of Things," in Procedia CIRP, 2017, vol. 63, pp. 307-312.

137.Y. S. Tan, Y. T. Ng, and J. S. C. Low, "Internet-of-Things Enabled Real-time Monitoring of Energy Efficiency on Manufacturing Shop Floors," in Procedia CIRP, 2017, vol. 61, pp. 376-381.

138.Z. Chen, X. Zhang, and K. He, "Research on the Technical Architecture for Building CPS and Its Application on a Mobile Phone Factory," in Proceedings - 2017 5th International Conference on Enterprise Systems: Industrial Digitalization by Enterprise Systems, ES 2017, 2017, pp. 76-84.

139.Z. Zhou, X. Liu, J. Pei, P. M. Pardalos, L. Liu, and C. Fu, "Real options approach to explore the effect of organizational change on IoT development project," Optim. Lett., vol. 11, no. 5, pp. 995-1011, 2017.

140.X. Liu, J. Pei, L. Liu, H. Cheng, M. Zhou, and P. M. Pardalos, Optimal Allocation of Decision-Making Authority in IoT-Based Manufacturing Enterprises, vol. 126. 2017.

141.Saranu J. , Shobharani D A, P. Sai Jyothi, G. Chandra M., Naga S. "IoT Based Coloured Products Sorting Machine" International Journal of Advanced Trends in Computer Science and Engineering, vol 9, No 2, 2020 https://doi.org/10.30534/ijatcse/2020/135922020

142.D. A. Martillano, J. M. R. Dita, C. G. Cruz, and K. S. Sadhra, "Android based real-time industrial emission monitoring system using IoT technology," J. Commun., vol. 12, no. 11, pp. 623-629, 2017.

143.E. Papahristou, P. Kyratsis, G. Priniotakis, and N. Bilalis, "The interconnected fashion industry - An integrated vision," in IOP Conference Series: Materials Science and Engineering, 2017, vol. 254, no. 17.

144.R. B. Obara and L. C. Guedes, "Fully Automated Quality Control of Cylinder Bores from Internal Combustion Engines and Its Implications for Industry 4.0," SAE Tech. Pap., vol. 2017-Novem, no. November, 2017.

145.G. De Oliveira Cordeiro, F. Deschamps, and E. P. De Lima, "Developing a big data/analytics project:
A case study in the auto industry," in 67th Annual Conference and Expo of the Institute of Industrial Engineers 2017, 2017, pp. 1753-1758.

146.H.-K. Lee and T. Kim, "Smart factory use case implemented for quality issues," ICIC Express Lett. Part B Appl., vol. 8, no. 1, pp. 221-226, 2017.

147.D. Bechtsis, N. Tsolakis, M. Vouzas, and D. Vlachos, Industry 4.0: Sustainable material handling processes in industrial environments, vol. 40. 2017.

148.M. Tu, W.-H. Chung, C.-K. Chiu, W. Chung, and Y. Tzeng, "A novel IoT-based dynamic carbon footprint approach to reducing uncertainties in carbon footprint assessment of a solar PV supply chain," in 2017 4th International Conference on Industrial Engineering and Applications, ICIEA 2017, 2017, pp. 249-254 